Dhaka Univ. J. Biol. Sci. 23(2): 157-164, 2014 (July)

\title{
EFFECTS OF PHOSPHORUS DEFICIENCY ON ION TRANSPORT AND ITS CORRELATION WITH SUGAR CONTENT AND ANATOMICAL STRUCTURE IN CHICKPEA (CICER ARIETINUM L. CV. BARI CHOLA-5) SEEDLINGS
}

\author{
Amatun Karim, Parveen Rashid, Rifat Samad and J. L. KarmokeR* \\ Department of Botany, University of Dhaka, Dhaka-1000, Bangladesh
}

Key words: Phosphorus deficiency, Ion transport, Anatomy, Chickpea

\begin{abstract}
Phosphorus deficiency stimulated accumulation of $\mathrm{Na}^{+}$in the root but declined in the shoot of chickpea seedlings. $\mathrm{K}^{+}$content in the root and the shoot increased initially followed by a decrease. Phosphorus deficiency inhibited the accumulation of $\mathrm{NO}_{3}-\mathrm{PO}_{4}^{3-}$ and also sugar content both in the root and shoot. It also caused a decline in the accumulation of total sugar only in the root. The interrelationship between the effect of phosphorus deficiency on ion transport and anatomical structure was discussed.
\end{abstract}

\section{Introduction}

Phosphorus $(\mathrm{P})$ provides indispensable foundation to agricultural production ${ }^{(1)}$. Plant cannot survive at phosphate concentration below two parts per ten million in soil solution $^{(2)}$. Phosphorus deficiency is one of the major limiting nutrition problems for plants, particularly in both acidic and calcareous soils where $\mathrm{P}$ retention and precipitation is maximum ${ }^{(3-4)}$.

Phosphorus deficiency inhibited accumulation of $\mathrm{K}^{+}$in the root and shoot but enhanced that of $\mathrm{Na}^{+}$both in the root and shoot of lentil(5), Pelargonium(6), bean ${ }^{(7)}$ and soybean ${ }^{(8)}$. It increased carbohydrate concentration in the root of bean ${ }^{(9)}$ and maize ${ }^{(10)}$. It decreased reducing sugar content in the leaves and stem but stimulated in the $\operatorname{root}^{(11)}$.

Phosphorus deficiency developed smaller radius of root and stem of spinach ${ }^{(12)}$ and maize ${ }^{(13)}$. It reduced number of xylem vessels in the root of Vigna seedlings ${ }^{(14)}$ and maize plant ${ }^{(13)}$.

Chickpea (Cicer arietinum, $2 \mathrm{n}=16$ ) is a legume of the family Fabaceae, was used as a plant material because reports on the effects of phosphorus deficiency on ion transport, reducing and total sugar contents are not sufficient. In this study the effect of phosphorus deficiency on the accumulation and distribution of $\mathrm{K}^{+}, \mathrm{Na}^{+}, \mathrm{NO}_{3}{ }^{-}, \mathrm{PO}_{4}{ }^{3-}$ and reducing and total sugars is reported.

\footnotetext{
*Author for correspondence <jlkarmoker48@gmail.com>
} 


\section{Materials and Methods}

Seeds of Cicer arietinum L. cv. BARI Chola-5 were collected from Bangladesh Agricultural Research Institute (BARI), Joydebpur, Gazipur. Chickpea seedlings were grown in a specialized nutrient solution ${ }^{(12)}$. Seeds were surface sterilized with $5.25 \%$ sodium hypochlorite solution for two min. Plastic lid covered with cotton gauze was placed upon the beaker painted block filled with nutrient solution. After $48 \mathrm{hrs}$ of sowing the seeds were germinated and then the germinated seeds were transferred to light bank at a day/night temperature of $25 \pm 1^{\circ} \mathrm{C} / 18 \pm 1^{\circ} \mathrm{C}$ and day/night length of $14 \mathrm{hrs} / 10 \mathrm{hrs}$ and light intensity was $160 \mu$-einstein $/ \mathrm{m}^{2} \mathrm{~s}$. The solution was replenished every $48 \mathrm{hrs}$. The solution was continuously aerated through bubbler with the help of air compressor. These seedlings were allowed to grow for ten days. Three uniform seedlings were transferred to a dunking frame $24 \mathrm{hrs}$ before the starting of the experiment. Solution containing P was used as control and solution free from P was used as P deficiency treatment and the plant samples were collected after 24, 48, 72 and $96 \mathrm{hrs}$.

$\mathrm{K}^{+}, \mathrm{Na}^{+}$and $\mathrm{NO}_{3}^{-}$in the root and shoot were extracted by water digestion and $\mathrm{PO}_{4}^{3-}$ was extracted by acid digestion. $\mathrm{K}^{+}$and $\mathrm{Na}^{+}$ions were measured using a flame analyzer (Jenway, PEP-7, UK) at wavelengths of 767 and $589 \mathrm{~nm}$, respectively. $\mathrm{NO}_{3-}^{-}$and $\mathrm{PO}_{4}{ }^{3-}$ were measured according to the method of Cataldo et al.(15) and Jackson ${ }^{(16)}$. Reducing sugar was measured following the methods of Somogyi(17) and Nelson ${ }^{(18)}$ and total sugar by phenol- $\mathrm{H}_{2} \mathrm{SO}_{4}$ method of Dubois et al. ${ }^{(19)}$.

\section{Results and Discussion}

Phosphorus deficiency increased the accumulation of $\mathrm{Na}^{+}$from 33 to $22 \%$ in the root of chickpea seedlings at $96 \mathrm{hrs}$ of treatment except a 52\% inhibition at $48 \mathrm{hrs}$ of treatment (Fig. 1a). But it reduced $\mathrm{Na}^{+}$content in the shoot gradually from 10 to $34 \%$ from 24 to 96 hrs of treatment (Fig. 1b). Initial stimulation in $\mathrm{Na}^{+}$accumulation may occur for compensation of the decrease in $\mathrm{K}^{+}$due to $\mathrm{P}$ deficiency ${ }^{(20)}$. Dinkelacker and Marschner ${ }^{(21)}$ reported similar phenomenon in the accumulation of $\mathrm{Na}^{+}$in the shoot of lentil seedlings. On the contrary, $\mathrm{P}$ deficiency was reported to enhance $\mathrm{Na}^{+}$accumulation in the shoot of lentil(5).

Phosphorus deficiency accelerated $\mathrm{K}^{+}$content in the root by $11 \%$ at $24 \mathrm{hrs}$ of treatment and this was nullified gradually within $96 \mathrm{hrs}$ of treatment (Fig. 2a). In the shoot, $\mathrm{K}^{+}$content was stimulated by $34 \%$ initially followed by $15 \%$ inhibition over the rest of the period of treatment (Fig. 2b). Dinkelacker and Marschner ${ }^{(21)}$ showed that phosphorus deficiency increased $\mathrm{K}^{+}$accumulation in the root but decreased in the shoot of chickpea. 

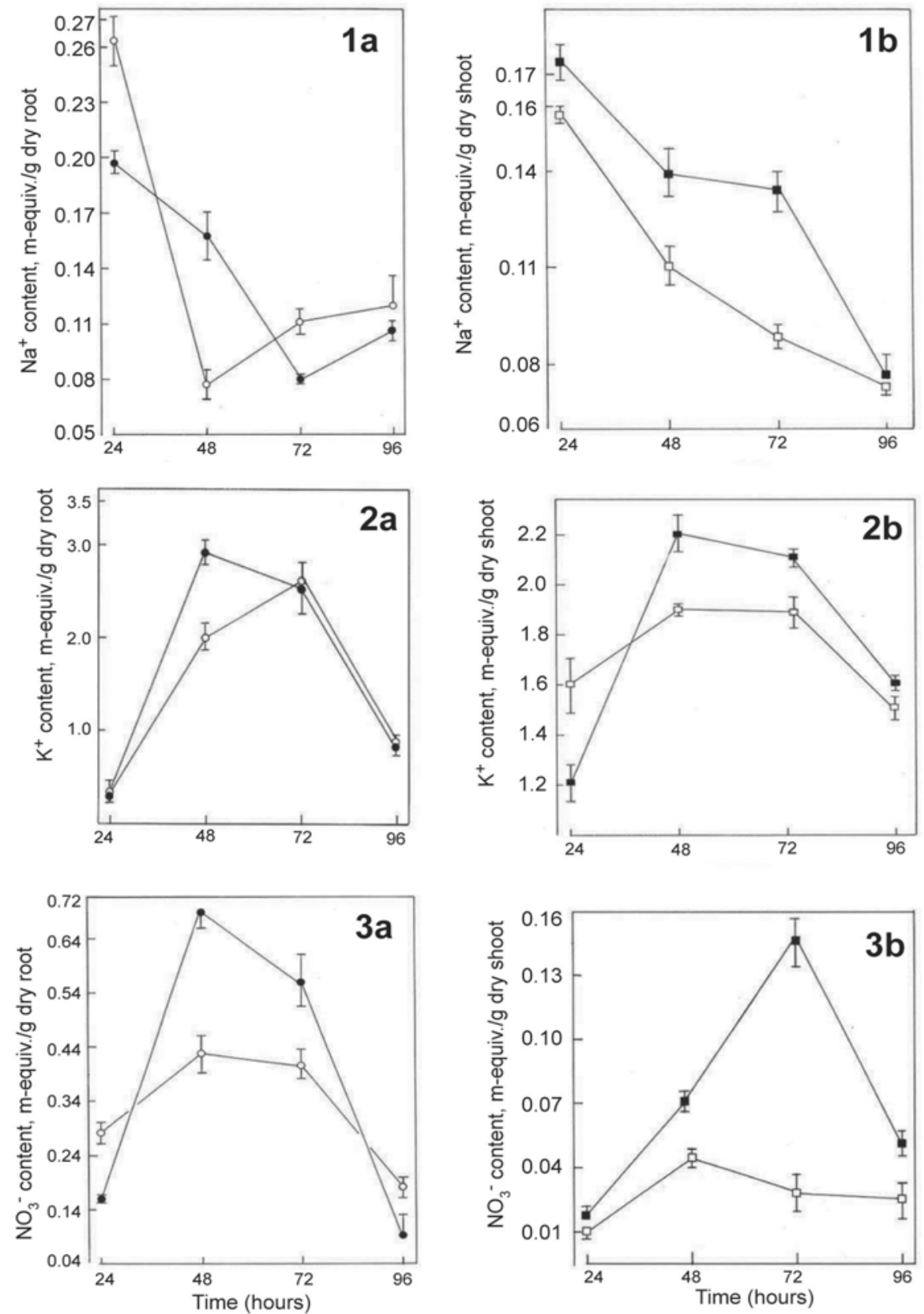

Figs 1 - 3: 1. Effects of phosphorus deficiency on the accumulation of $\mathrm{Na}^{+}$in the root (a) and shoot (b) of chickpea seedlings. Solid symbols represent control and open symbols represent treatment. Bars represent \pm standard error. 2. Effects of phosphorus deficiency on the accumulation of $\mathrm{K}^{+}$in the root (a) and shoot (b) of chickpea seedlings. Otherwise as Fig. 1. 3. Effects of phosphorus deficiency on the accumulation of $\mathrm{NO}_{3}$ in the root (a) and shoot (b) of chickpea seedlings. Otherwise as Fig. 1. 

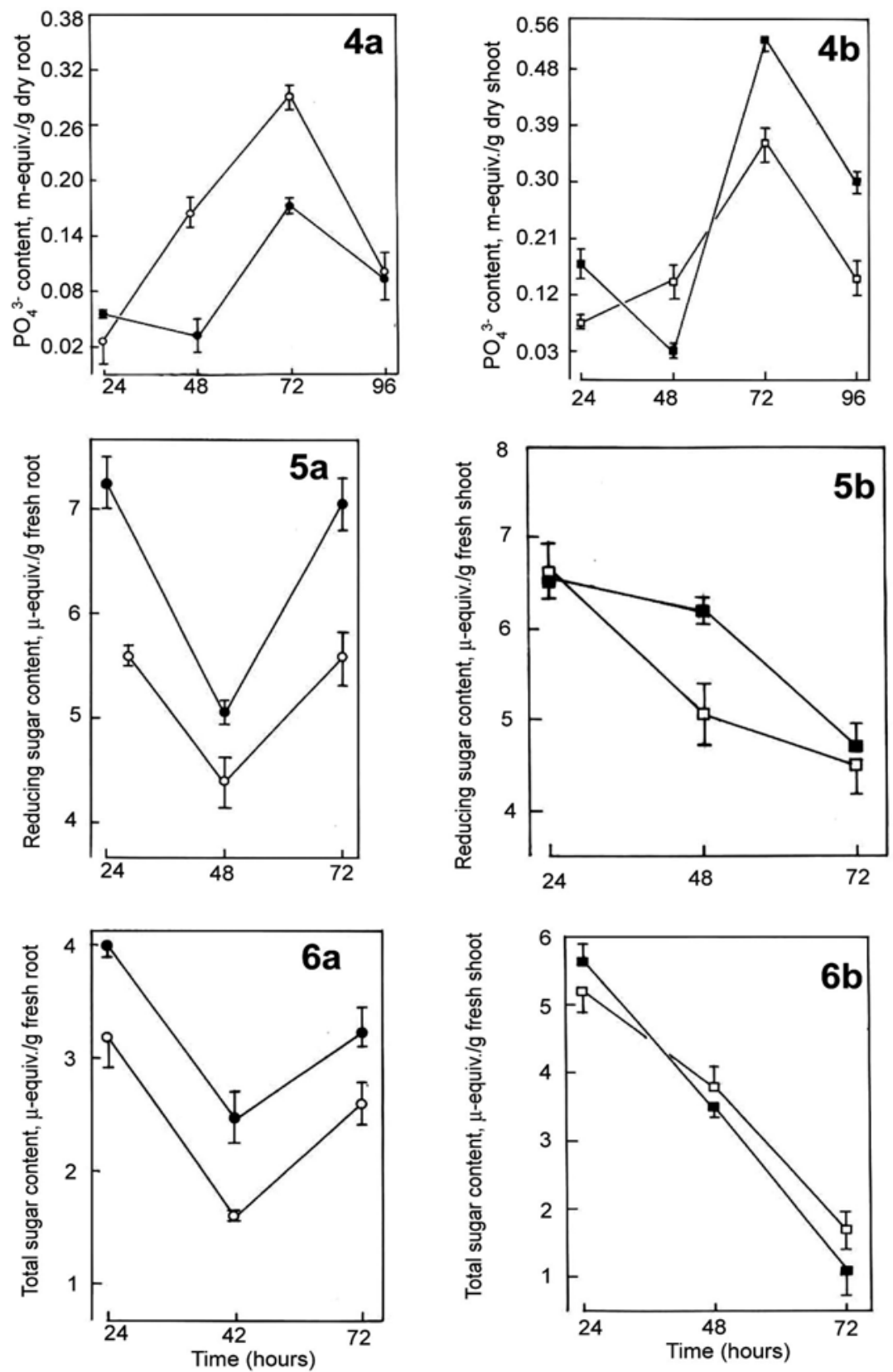

Figs 4 - 6: 4. Effects of phosphorus deficiency on the accumulation of $\mathrm{PO}_{4}^{3-}$ in the root (a) and shoot

(b) of chickpea seedlings. Solid symbols represent control and open symbols represent treatment. Bars represent \pm standard error. 5. Effects of phosphorus deficiency on the accumulation of reducing sugar in the root (a) and shoot (b) of chickpea seedlings. Otherwise as Fig. 4. 6. Effects of phosphorus deficiency on the accumulation of total sugar in the root (a) and shoot (b) of chickpea seedlings. Otherwise as Fig. 4. 
Accumulation of $\mathrm{NO}_{3}$ - was declined from 85 to $36 \%$ in the root from 48 to $96 \mathrm{hrs}$ of treatment except an initial acceleration by $38 \%$ at $24 \mathrm{hrs}$ of treatment (Fig. 3a). In the shoot, $\mathrm{NO}_{3}{ }^{-}$content showed a reduction under P-deficiency (Fig. 3b). Similarly, Pdeficiency increased $\mathrm{NO}_{3}{ }^{-}$accumulation in the root but decreased that in the shoot in maize ${ }^{(22)}$, bean ${ }^{(23)}$ and Ricinus communis(24).

Phosphorus deficiency caused an increase in $\mathrm{PO}_{4} 4^{3-}$ content in the root up to $57 \%$ over a period of $96 \mathrm{hrs}$ of treatment (Fig. 4a) with a concomitant decline in the shoot over the same time period (Fig. 4b). Similarly an inhibition in phosphate content in the root and shoot was observed by Dinkelaker and Marschner (21) in chickpea and Andreeva et al. ${ }^{(25)}$ in mustard following P deficiency.

Phosphorus deficiency lowered reducing sugar content in the root from 24 to $72 \mathrm{hrs}$ treatment (Fig. 5a ) but it had no effect on shoot except a 18\% inhibition at $48 \mathrm{hrs}$ of treatment (Fig. 5b). Similarly, it decreased reducing sugar in the leaves and stem but stimulated that in the $\operatorname{root}^{(11)}$.

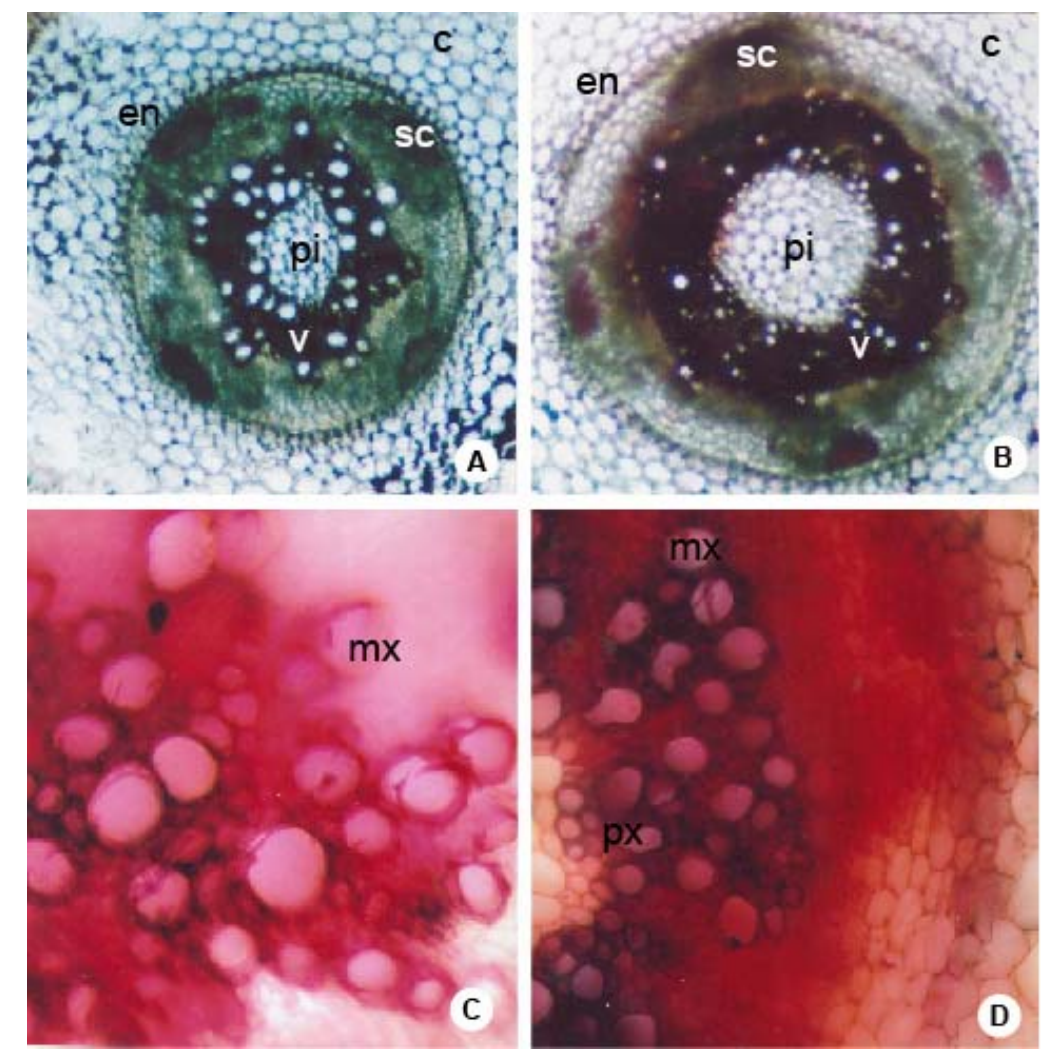

Fig. 7. TS of root of 40-day-old chickpea grown in sand culture with phosphorus (control $(\mathrm{A}, \mathrm{C})$ and without phosphorus $(\mathrm{B}, \mathrm{D}) . \mathrm{c}=$ cortex; $\mathrm{en}=$ endodermis; $\mathrm{mx}=$ metaxylem; $\mathrm{pi}=\mathrm{pith}, \mathrm{px}=$ protoxylem; $\mathrm{sc}=$ sclerenchyma and $\mathrm{v}=$ vessel. $(\mathrm{A}, \mathrm{B}=100 \mathrm{x}, \mathrm{C}, \mathrm{D}=400 \mathrm{x})$ 
Phosphorus deficiency caused a reduction in total sugar content in the root from 21$22 \%$ from 24 to $72 \mathrm{hrs}$ of treatment (Fig. 6a) but it enhanced that in the shoot by 10 and $42 \%$ at 48 and $72 \mathrm{hrs}$ of treatment, respectively (Fig. $6 \mathrm{~b}$ ). On the other hand, it increased total sugar content in roots of bean ${ }^{(9)}$ and maize ${ }^{(10)}$.
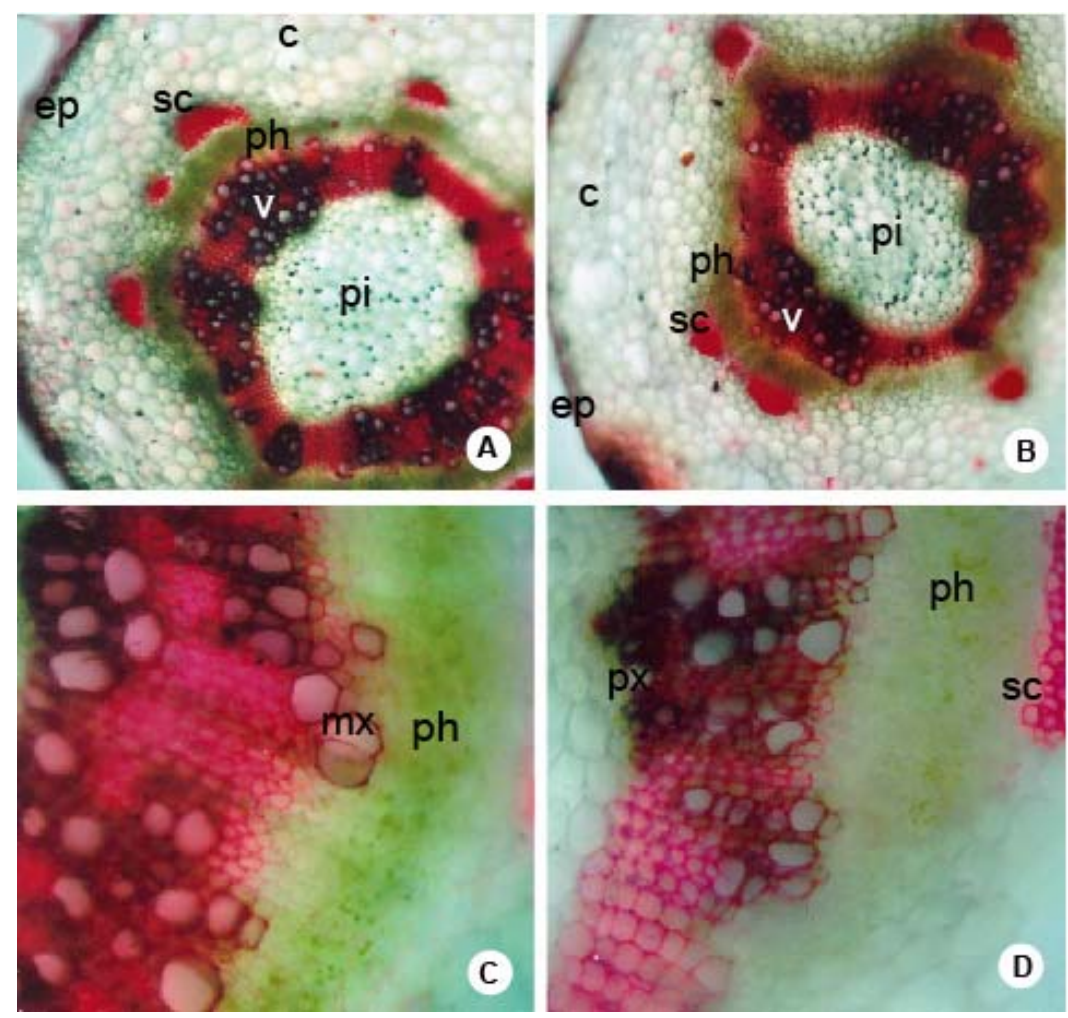

Fig. 8. TS of stem of 40-day-old chickpea grown in sand culture with phosphorus $(\mathrm{A}, \mathrm{C})$ (control) and without phosphorus $(\mathrm{B}, \mathrm{D}) . \mathrm{c}=$ cortex; ep = epidermis; en = endodermis; $\mathrm{mx}=$ metaxylem; $\mathrm{ph}=$ phloem; $\mathrm{pi}=\mathrm{pith}, \mathrm{px}=$ protoxylem; $\mathrm{sc}=$ sclerenchyma and $\mathrm{v}=$ vessel. $(\mathrm{A}, \mathrm{B}=100 \times$, $\mathrm{C}, \mathrm{D}=400 \times)$

Layers of cortical cells were less in stem of control plant (Fig. 8A,C) and thickening of endodermis in root was observed in the phosphorus-deficient plant (Fig. 7B). Thickwalled endodermal cells were reported in maize under phosphorus deficiency ${ }^{(13)}$. Vascular bundles with less number of xylem vessels and also smaller vessel cavity were recorded in roots and shoots of plants raised under phosphorus deficiency condition (Fig. 7B, D and Fig. 8B, D) compared to control (Fig. 7A, C and Fig. 8A, C). Liu et al.(14) investigated anatomical structures in the seedlings of Vigna unguiculata ssp. sesquipedalis under phosphorus deficiency and also observed less number of xylem vessels. Lovelock et al.(26) also found that addition of phosphorus to P-deficient dwarf mangroves increased the diameter of xylem vessels and area of conductive xylem tissue. 
Phosphorus deficiency induced reduction in the number of xylem vessels in vascular system and size of xylem cavity (Fig. 8B, D) may lead to the observed decrease in translocation of $\mathrm{K}^{+}$and $\mathrm{NO}_{3}^{-}$(Fig. $2 \mathrm{~b}$ and $3 b$ ).

\section{References}

1. Nagarjan VK, A Jain, MD Poling, AJ Lewis, KG Raghothama and AP Smith 2011. Arabidopsis Pht1; 5 mobilizes phosphate between source and sink organs and influences and interaction between phosphate homeostasis and ethylene signaling. Plant Physiol. 156: 1149-1163.

2. Nautiyal N, BK Dubey and C Chatterjee 2000. Symtoms of nutrient deficiency (N, P, Ca, Mg and S) in sugarcane grown in refined sand. Sugarcane International, March. pp. 12-17.

3. Marschner H 1995. Mineral Nutrition of Higher Plants. $2^{\text {nd }}$ ed. Academic Press, London. pp. 889.

4. Hinsinger P 2011. Bioavailability of soil inorganic P in the rhizosphere as affected by rootinduced chemical changes: A review. Plant Soil 237: 173-195.

5. Sarker BC and JL Karmoker 2011a. Effect of phosphorus deficiency on growth and transport of $\mathrm{K}^{+}, \mathrm{Na}^{+}, \mathrm{Cl}, \mathrm{NO}_{3}-$ in lentil seedling (Lens culinaris Medik. var. Barimasur-4). Dhaka Univ. J. Biol. Sci. 2: 103-108.

6. Taylor MD, PV Nelson, JM Frantz and TW Rufty 2010. Phosphorus deficiency in Pelargonium: Effects on nitrate and ammonium uptake and acidity generation. J. Plant Nutr. 33: 701712 .

7. Gniazdowska A and AM Rychter 2000. Nitrate uptake by bean (Phaseolus vulgaris L.) roots under phosphate deficiency. Plant Soil 226: 79-85.

8. Rufty TW, DW Israel, RJ Volk, J Qiu and T Sa 1993. Phosphate regulation of nitrate assimilation in soybean. J. Expt. Bot. 44: 879-891.

9. Ciereszko I, A Gniazdowska, M Mikulska and AM Rychter 1996. Assimilate translocation in bean plants (Phaseolus vulgaris L.) during phosphate deficiency. J. Plant Physiol. 149: 343-348.

10. Khamis S, S Chaillou and T Lamaze 1990. $\mathrm{CO}_{2}$ assimilation and partitioning of carbon in maize plants deprived of orthophosphate. J. Expt. Bot. 41: 1619-1625.

11. Sarker BC and JL Karmoker 2011b. Effects of phosphorus deficiency on accumulation of biochemical compounds in lentil (Lens culinaris Medik.). Bangladesh J. Bot. 40: 23-27.

12. Fohse D, N Claassen and A Jungk 1991. Phosphorus efficiency of plants. II. Significance of root radius, root hairs and cation-anion balance for phosphorus influx in seven plant species. Plant Soil 132: 261-272.

13. Sarker BC, JL Karmoker and Parveen Rashid 2010. Effects of phosphorus deficiency on anatomical structures in maize (Zea mays L.). Bangladesh J. Bot. 39: 57-60.

14. Liu HC, GJ Chen, RY Chen, YH Kuang and XY Wu 2004. Anatomical structures of seedlings of Vigna unguiculata sp. sesquipedalis cultivars under phosphorus deficiency stress. J. Plant Resour. Environ. 3: 48-52.

15. Cataldo DA, M Haroon, LE Schrader and VL Youngs 1975. Rapid colorimetric determination of nitrate in plant tissue by nitration of salicyclic acid. Commun. Soil Sci. Plant Anal. 6: 71-80. 
16. Jackson ML 1967. Phosphorus determination for soils. In: Soil Chemical analysis - Advanced Course (Jackson ML and P Barak Eds.). Revised 2 ${ }^{\text {nd }}$ Edition. pp. 151-156. Parallel Press, Madison, Wisconsin.

17. Somogyi M 1952. Notes on sugar determination. J. Biol. Chem. 195: 19-23.

18. Nelson N 1944. A photometric adaptation of the Somogyi method for determination of glucose. J. Biol. Chem. 153: 375-380.

19. Dubois M, KA Gilles, JK Hemilton, PA Rebers and F Smith 1956. Colorimetric method for determination of sugars and related substances. Ann. Chem. 28: 350-356.

20. Nasreen L 1999. The effect of phosphorus deficiency on the transport of ions and exudations of citric acid in lentil (Lens culinaris cv. Barimossour-4) seedlings, M.Sc. Thesis, University of Dhaka.

21. Dinkelacker B and H Marschner 1992. Excretion of citrate and malate in the rhizosphere of chickpea (Cicer arietinum): Influence of phosphorus supply and N source. University of Hohenheim, Germany.

22. Sarker BC 2008. The effect of phosphorus deficiency on ion transport and its correlation with biochemical changes and anatomical structure in Zea mays L. and Lens culinaris Medik. Ph.D. Thesis, University of Dhaka, Bangladesh.

23. Gniazdowska A, A Krawczak, M Mikulska and AM Rychter 1999. Low phosphate nutrition alters bean plants ability to assimilate and translocate nitrate. J. Plant Nutr. 22: 551-563.

24. Jeschke WD, A Peuke, EA Kirkby, JS Pate and W Hartung 1996. Effects of P deficiency on the uptake, flows and utilization of $\mathrm{C}, \mathrm{N}$ and $\mathrm{H}_{2} \mathrm{O}$ within intact plants of Ricinus communis. L. J. Expt. Bot. 47: 1737-1754.

25. Andreeva TF, SM Maevskaya and SYU Voevudskaya 1992. Interrelationship between photosynthesis, nitrogen metabolism and growth in mustard plants under stress and adaptation to the prolonged action of high $\mathrm{CO}_{2}$ concentration and increasing phosphorus deficiency. Fiziologiya-i-Biokhimiya Kul'turnykh Rastenii. 24: 27-34.

26. Lovelock CE, MC Ball, B Choat, BMJ Engelbercht, NM Holbrook and IC Feller 2006. Linking physiological processes with mangrove forest structure: Phosphorus deficiency limits canopy development, hydraulic conductivity and photosynthetic carbon gain in dwarf Rhozophora mangle. Plant Cell Environ. 29: 793-802.

(Manuscript received on 8 October, 2013; revised on 1 February, 2014) 
